\title{
MARHAENISM: SOCIAL IDEOLOGY CREATE BY SUKARNO
}

\author{
Kuswono \\ Pendidikan Sejarah FKIP Universitas Muhammadiyah Metro \\ Email: kuswono@ummetro.ac.id
}

\begin{abstract}
Abstrak
Tulisan ini memaparkan sebuah pemahaman yang terlahir di negeri terjajah yakni Indonesia (Hindia Belanda) untuk menentang kolonialisme, kapitalisme dan imperialisme pada awal abad keduapuluh. Marhaenisme, Sukarno menyebut ideologi tersebut. Tujuan penulisan ini adalah memberikan pemahaman mengenai ideologi politik yang berkembang jaman pergerakan awal abad keduapuluh. Sampai saat ini Marhaenisme masih menarik untuk dikaji dan dipahami bahkan diterapkan dalam kehidupan berbangsa dan bernegara. Tulisan menggunakan metode sejarah bersifat deskriptif-analisis. Sumber data didapatkan dari berbagai literatur, bahan pustaka, dan tulisan-tulisan Sukarno sebagai pengagas ideologi ini. Marhaenisme merupakan ideologi perlawanan terhadap kolonialisme dan imperialisme asing. Dengan semangat Marhaen Sukarno berharap bangsa terjajah akan segera bangkit dari keterpurukan. Kemudian mampu mengolah, menikmati hasil jerih payahnya sendiri tanpa harus tunduk pada orang lain. Marhaenisme tidak hanya sekedar simbol kebangkitan wong cilik melainkan sebuah semangat jiwa seluruh rakyat Indonesia yang bebas dari penjajahan fisik dan mental yang datang dari luar.
\end{abstract}

Kata kunci: Marhaenisme, Ideologi, Sukarno

\begin{abstract}
This paper describes an understanding born in the occupied country, namely Indonesia (Dutch East Indies) to oppose colonialism, capitalism and imperialism in the early twentieth century. Marhaenisme, Sukarno call that ideology. The purpose of this paper is to provide an understanding of the political ideology that developed early days of the movement of the twentieth century. Until now Marhaenism still interesting to be studied and understood even applied in the life of the nation. Writings using the historical method is descriptive-analysis. Sources of data obtained from the literature, library materials, and writings by Sukarno as the originator of this ideology. Marhaenism an ideology of opposition against colonialism and foreign imperialism. With the spirit of Sukarno hoped Marhaen colonized people will soon emerge from the downturn. Then able to process, enjoy the fruits of his labors without having to submit to someone else. Marhaenism not just a symbol of resurrection of the wong cilik but a spirit of all the people of Indonesia that is free from physical and mental colonization coming from the outside.
\end{abstract}

Keyword: Marhaenism, Ideology, Sukarno

\section{PENDAHULUAN}

Ideologi menjadi begitu penting

jika dikaitkan dengan sistem

pemerintahan atau kekuasaan tertentu

dalam suatu negara. Setiap pergantian

pemerintahan yang menjadi pergumulan

adalah ideologi yang berpengaruh dalam diri penguasa tersebut. Ide merupakan sebuah pemikiran yang dihasilkan dari renungan seseorang melalui berbagai pertimbangan dan kebijakan yang ada dalam dirinya dan dipengaruhi oleh jiwa jaman untuk diaplikasikan dalam 
kehidupannya, masyarakat, bangsa dan negaranya. Sukarno sosok pejuang dalam masa pergerakan dan kemerdekaan tidak terlepas usahanya untuk mencapai kemerdekaan. Pada masa kolonial Belanda, Sukarno tidak segan-segan melawan secara terangterangan terhadap berbagai kebijakan pemerintah Hindia Belanda. Keberpihakannya terhadap kaum pribumi yang melarat dan penuh kesengsaraan menginspirasi Sukarno membentuk sebuah partai radikal (PNI) dan mengembangkan pemikirannya mengenai konsep Marhaenisme.

Marhaenisme diperkenalkan semasa jaman pergerakan dalam suasana kehidupan ekonomi rakyat dikuasai oleh modal produksi kolonial, dimana rakyat hanya diperlakukan sebagai pekerja upahan. Sukarno melihat ada petani kecil yang tetap menguasai alat-alat produksi pertaniannya yang mampu bertahan dalam keterbatasannya, sehingga dapat digeneralisasikan menjadi kondisi rakyat Indonesia yang dapat digerakan kearah masyarakat yang maju. Sebagai sebuah ideologi, Marhaenisme menjadi penentang rezim kolonial yang kapitalistis, dimana sebagian besar alat-alat produksi (sumber daya alam dan modal) dikuasai oleh penguasa dan pemodal besar (Soeseno, dalam www.marhaenisme.com diunduh Pada 24 September 2011.).
Bagi Sukarno, Marhaen bukan hanya melambangkan perwakilan terbaik kelas bawah layaknya partai buruh di negara-negara maju, misalnya bagi kaum proletar (buruh, buruh tani, pengrajin, dsb). Sukarno menganggap Marhaen mewakili mayoritas rakyat kecil Indonesia yang pada umumnya hidup termarjinalkan. Bahkan, eksistensi mereka pun sangat rapuh. Mereka berada diambang batas kelangsungan hidupnya, sebagian besar kebutuhan materi, ekonomi, sosial dan politiknya hampir sama sekali tidak terpenuhi. Mayoritas orang Indonesia hidup menderita dan menghadapi resiko eksistensial dari waktu kewaktu. Inilah rakyat Indonesia yang tidak mampu untuk memenuhi standar hidup minimal, hilangnya standar keamanan dan keadilan dalam kehidupannya yang notabene hidup di kampungnya sendiri.

\section{METODE PENELITIAN}

Penelitian ini mengguanakan metode historis dengan langkah langkah heuristik, kritik sumber, interpretasi dan penulisan sebagai langkah terakhir. Sumber data didapatkan dari berbagai literatur, bahan pustaka, dan tulisantulisan yang ditulis oleh Sukarno sebagai pengagas ideologi ini.

\section{HASIL DAN PEMBAHASAN}

Buah Pikiran Sukarno Masa Pergerakan 
Tampaknya Sukarno mempunyai kesimpulan serupa dengan Cliford Geertz mengenai involusi ketika membalikan kesimpulan J.H. Boeke mengenai dualisme ekonomi. Sukarno menyatakan bahwa masyarakat desa di Jawa telah menjadi miskin oleh penjajahan, sehingga mereka menjadi statis hampir tak ada perubahan dalam kehidupannya. Walaupun Sukarno mengerti dan membedakan antara imperialisme kuno dan modern, tetapi pada hakekatnya adalah sama, yaitu nafsu menguasai atau mengendalikan perekonomian bangsa dan negara lain untuk kepentingan kekuasaan kolonial, dimana kepentingan imperialisme bertentangan dengan kepentingan negara satelit. Negara penjajah mempertahankan kekuasaannya agar dapat menguras sebanyak mungkin sumber daya alam, sedangkan negara terjajah ingin secepatnya membebaskan diri dari cengkraman nafsu imperialisme. Namun, Sukarno kurang berminat berbicara mengenai nilai-nilai positif dalam imperialisme.

Di mata Sukarno, imperialisme penuh dengan tipu daya yang membutakan rakyat dengan keterbelakangan. Kebencian Sukarno terhadap Imperialisme dituangkan melalui tulisannya yang diberi judul "Nasionalisme, Islamisme dan Marxisme" menyerukan agar ketiga kelompok aliran tersebut bersatu menghancurkan imperialisme yang dimanifestasikan kekuasaan kolonial Hindia Belanda. "Bukannya kita mengharap yang nasionalis itu supaya berubah paham menjadi Islamis atau Marxis, bukannya maksud kita menyuruh Marxis dan Islamis berbalik menjadi Nasionalis, akan tetapi impian kita ialah kerukunan, persatuan antara tiga golongan tersebut" (Soekarno, 1964: 5).

Ketiga paham tersebut memang mempunyai kekuatan yang besar pengaruhnya dikalangan pribumi termasuk dalam jiwa Sukarno. Nurani Soyomukti (2008:80) berpendapat bahwa pemikiran Islam Sukarno banyak dipengaruhi oleh Haji Misbach sebab banyak pemikiran dari Sukarno tentang Islam yang hampir sama dengan Haji Misbach. Selain itu, Sukarno banyak berguru bahkan hidup bersama dengan Cokroaminoto, kemungkinan dari pemikiran Cokroaminoto tersebut paham Sukarno tentang Islam terbentuk. Selain dengan Cokroaminoto, Sukarno dekat juga dengan Ahmad Hasan (Hasan Bandung) pendiri Persatuan Islam (Persis) sebagai guru spiritualnya. Sukarno menaruh perhatian terhadap penghisapan ekonomi, diskriminasi dan penghancuran nilai-nilai sosial yang menyertai imperialisme, dan itu (antiimperialisme) adalah salah satu bentuk pandangan politik Sukarno yang tetap dipertahankan sampai dia menjadi orang 
nomor satu di Indonesia setelah kemerdekaan.

Sukarno melihat disemua negeri terjajah, termasuk di Indonesia, perjuangan melawan kolonial ini ada dua warna yang dominan yaitu dengan bendera Islam ataupun bendera Sosialis (Marxis). Sukarno mengakui bahwa Islamisme dan Marxisme adalah ideologi yang lintas bangsa tetapi benang merah yang diambil Sukarno adalah semua perjuangan diberbagai negeri adalah sama yaitu untuk memerdekakan negerinya dari kolonialisme dan imperialisme. Maka dari itu Sukarno selalu menekankan bahwa segala macam warna perjuangan yang ada di Indonesia adalah untuk Tanah Air Indonesia, semua harus bersatu, bahu-membahu demi Tanah Air tempat dimana Bangsa Indonesia hidup.

Dalam perjalanannya konsep Nasionalis, Islamisme, dan Marxisme Sukarno berubah menjadi Nasakom; Nasionalis, Agama, dan Komunis. Sukarno memperluas konsep Islamisme menjadi Agama, yang harapanya semua agama bisa terwakili dalam konsep persatuannya tersebut. Sukarno benarbenar berusaha sekuat tenaga untuk mewujudkan kebhinekaan tiga golongan ini menjadi Tunggal lka, dalam balutan Ibu pertiwi walau sebenarnya Sukarno sadar benar golongan-golongan ini rentan sekali bertikai karena perbedaan paham yang sangat lebar.
Sukarno melihat bahwa keterbelakangan negara di Dunia Ketiga adalah akibat keserakahan dari negaranegara yang tidak pernah puas dan selalu mengadakan penghisapan terhadap bangsa-bangsa yang dilanda kelaparan dan kemiskinan. Walaupun pemahaman sosialis begitu menonjol dalam pemikiran Sukarno tampaknya dia tidak menggantungkan konsep-konsep pemikirannya secara kuat pada salah seorang pemikir sosialis tertentu, seperti Bauer, Brailsford, Engels, Jaures, Kaustky, Marx dan Troelstra, melainkan sesuai dengan kebutuhannya untuk mengemukakan atau mempertajam konsep-konsepnya sendiri (Peter Kasenda, 2011). Sukarno memadukan antara Nasionalisme, Sosialisme dan Islamisme yang merupakan paham-paham yang berkembang di Hindia Belanda awal abad keduapuluhan.

\section{Munculnya Marhaenisme Awal Abad ke-20}

Kebijakan Pemerintah Hindia Belanda yang tidak berpihak kepada mayoritas pribumi sepertinya membuat Sukarno gerah. Segenap pikirannya terus dicurahkan untuk mendapatkan cara melakukan sebuah terobosan yang mempunyai dukungan dari kalangan mayoritas penduduk Hindia Belanda (Indonesia). Situasi yang serba memprihatinkan bagi rakyat kebanyakan 
sepertinya lebih mengispirasi Sukarno merumuskan pemikirannya mengenai Marhaenisme. Kebanyakan rakyat ketika itu hidup sebagai masyarakat sublatern bahkan lebih dari itu yakni masyarakat melarat. Masyarakat sublatern menurut Gramsci adalah term sebagai kelompok yang kalah dan terpinggirkan dalam kekuasaan (sebagai kelompok inferior) yang didalamnya adalah petani, buruh, dan kelompok yang tidak mempunyai akses pada kekuasaan (I Ngurah Suryawan, 2010: 82).

Ranajit Guha mengatakan bahwa masyarakat subaltern adalah kelompok non-elit kelompok yang bukan penguasa. Gayatri Chakravarthy Spivak dalam bukunya yang berjudul Can The Subaltern Speak? mengatakan bahwa masyarakat subaltern adalah mereka yang bukan elit dan kaum yang tidak bisa bicara karena tidak diberi hak dalam wacana kolonialisme. Subaltren adalah mereka yang selalu dalam posisi dipresentasikan oleh pihak-pihak yang berkepentingan seperti politik, birokrat, sementara mereka tidak bisa mempresentasikan dirinya sendiri karena akses yang tidak dimilikinya. Atau bahkan masyarakat subaltern dalam kelompok yang tidak berdaya dan tidak dapat berbicara di media publik dan sifat marginal (petani, pekerja, wong cilik) (I Ngurah Suryawan, 2010:20). Konsep tersebut tentu begitu sesuai dengan kondisi masyarakat yang dilihat Sukarno pada masa kolonial, dimana masyarakat terbungkam oleh kaum kapitalis barat dan priyayi pribumi.

\section{Konsep Marhaenisme}

Ajaran Marhaenisme telah dicetuskan tahun 1927 suatu ajaran yang menurut Sukarno mengandung ilmu perjuangan revolusioner untuk menggalang persatuan kaum Marhaen. Kata Marhaen mulai mencuat ketika Sukarno melakukan pembelaannya dihadapan raad van indie di Bandung tahun 1930. Marhaen berasal dari nama seorang petani miskin yang mempunyai lahan dan alat pertanian sendiri di daerah Jawa Barat. Sampai pada akhir 1930, ungkapan yang lazim bagi "orang kecil" adalah "kromo" tetapi sejak permulaan propaganda PKI istilah tersebut sering dipakai mengacu pada kaum proletar, hal tersebut memaksa Sukarno untuk mencari istilah baru.

Ada dua versi mengenai munculnya istilah marhaen. Pertama, Marhaen adalah seorang petani di daerah Bandung yang memiliki sebidang tanah kemudian menggarap sendiri, alatnya punya dia sendiri dan hasilnya cukup untuk kebutuhan keluarganya. Pada suatu hari, ketika sedang jalan-jalan di daerah Kiduleuen, Cigelereng, Bandung Selatan. Sukarno berjumpa dengan seorang petani yang sedang mengerjakan sawah miliknya sendiri 
dengan alat-alat yang dimiliki sendiri walaupun sederhana, seperti dijelaskan oleh Sukarno dikemudian hari, jelas gambaran sosok petani diatas bukan proletar (karena ia tidak menjual tenaganya), tetapi walaupun demikian hidupnya dalam kemiskinan. Sukarno menanyakan namanya, Marhen, jawab si petani. (Bernhard Dahm a.b. Hasan Basri, 1987:175). Dari situlah Sukarno mulai menggunakan kata Marhaen sebagai sebuatan untuk rakyat miskin kebanyakan yang berada di bawah tekanan dibawah kekuasaan kolonial. Dalam berbagai pidatonya Sukarno yakin bahwa kemerdekaan akan tercapai jika rakyat Marhaen bersatu dalam sebuah wadah organisasi yang baik. Tanpa itu kemerdekaan sulit dicapai sehingga mutlak dibutuhkan sebuah ideologi revolusioner (Juti, 1964:8).

Versi yang kedua, mengatakan Marhaen berasal dari akronim Marx, Hegel dan Engels. Versi ini mempunyai alasan bahwa arah pemikiran Sukarno mengenai Marhaenisme berpijak pada teori dialektika yang dikembangkan oleh Hegel dan didukung oleh Karl Marx dan F. Engels. Bahkan menurut Ruslan Abdulgani jika akan mengmahami Marhaenisme maka orang tersebut harus paham Marxsisme terlebih dahulu (Yulianto Sigit Wibowo, 2005:73)

Konsep Marhaen yang dirumuskan Sukarno, tentu berbeda dengan konsep proletarnya Karl Marx. Disini terlihat
Sukarno bersifat kritis tidak begitu saja mengambil konsep yang dilontarkan pemikir-pemikir sosialis Barat. Konsep proletar hanya mempunyai relevansi di negara-negara industri Barat, untuk masyarakat Indonesia yang merupakan masyarakat agraris tidak memungkinkan.

Terdapat perbedaan konsep Marhaen dengan proletar, konsep Marhaen mewakili sebagian besar anggota masyarakat yang sengsara dan tertindas, sedangkan Proletar hanya mencakup sedikit anggota masyarakat saja yakni buruh. Selain itu, yang membedakan keduanya adalah kaum Marhaen yang memiliki alat produksi, tetapi kaum proletar tidak memiliki alat produksi dan hanya menjual jasa. Melalui Marhaenisme sebagai teori perjuangan dipakainya untuk mengubur sistem kapitalisme maupun imperialisme dari muka bumi Indonesia yang kaya sumber alamnya, tetapi rakyatnya miskin. (Peter Kasenda dalam www. peterkasenda. wordpress. com. Di akses pada 29 September 2011. hlm. 51).

Sukarno dalam menjelaskan Marhaenisme tidak pernah keluar dari benang merah yang telah digariskan sejak tahun 1927 tentang Marhaenisme, diantaranya:

1. Marhaen adalah kaum melarat Indonesia, yang terdiri dari buruh, tani, pengusaha kecil, pegawai kecil, tukang, kusir, dan 
kaum kecil lainnya. Sukarno sering menyebutkan Marhaen adalah rakyat Indonesia yang dimiskinkan oleh imperialisme.

2. Marhaen Indonesia ada yang berdomisili di pantai, di gunung, di dataran rendah, di kota, di desa dan di mana saja. Marhaen itu ada yang beragama Islam, Kristen, Hindu, Budha, dan ada juga yang menganut animisme.

3. Kaum Marhaen, sesuai dengan kodratnya, berupaya melepaskan belenggu kemiskinan dan mengharapkan terjadinya perbaikan nasib.

4. Marhaenisme adalah ideologi yang bertujuan menghilangkan penindasan, penghisapan, pemerasan, penganiayaan dan berupaya mencapai serta mewujudkan masyarakat yang adil dan makmur, melalui kemerdekaan nasional, melalui demokrasi politik dan demokrasi ekonomi.

5. Terhapusnya kemiskinan dan terwujudnya masyarakat adil dan makmur, hanya bisa dicapai dengan kemerdekaan nasional, dimana kemerdekaan itu hanyalah jembatan emas. Di seberang jembatan emas itu terbuka dua jalan. Satu jalan menuju masyarakat yang adil dan makmur, dan jalan satu lagi menuju masyarakat celaka dan binasa (Yuddy Chrisnandi, dalam www. marhaenisme.com, diakses pada 24 September 2011).

Menurut putusan Partindo, Marhaenisme yakni sosio-nasionalisme dan sosio-demokrasi, yang beranggotakan kaum proletar, pertani dan kaum melarat lainnya, Marhaenisme merupakan juru selamat untuk kaum Marhaen, Marhaenisme merupakan azas yang menghendaki susunan masyarakat yang menyelamatkan kaum Marhaen, perjuangan revolusioner adalah jalan yang ditempuh untuk mencapai masyarakat Marhaen, perjuangan tersebut yakni menghancurkan imperialisme dan kapitalisme (Sukarno, 1964:253).

Penyebaran paham-paham baru banyak dirasakan kaum jelata (rakyat kecil) dari berbagai media massa melalui kaum kelas menengah. Berbagai organisasi muncul secara modern yang mempegaruhi kehidupan masyarakat dengan hal-hal baru. Tokoh seperti Marco Kartodikromo, Cipto Mangunkusumo, Haji Misbach, dan Semaun banyak tampil dikalangan masyarakat kecil dan mempengaruhi pola pikir rakyat untuk menentang kolonialisme dengan pemogokan dan mendirikan sekolah atau kursus politik untuk rakyat (Nurani Soyomukti, 2008:80). Melalui media massa Fikiran Rakjat Marhaenisme berkembang, 
Sukarno mencoba mengembangkan pemikiran tersebut sebagai gerakan nonkooperatif.

\section{Asas Marhaenisme}

Pemikiran Sukarno terpengaruh oleh paham Marxis. Menurut Sukarno untuk memahami konsep Marhaenisme maka harus mengerti dua hal yakni pengetahuan tentang situasi dan kondisi Indonesia, serta pengetahuan tentang Marxisme (Imam Toto K. Raharjo dan Herdianto WK, 2001:226.). Dalam sebuah pidato memperingati HUT Marhaenisme 4 Juli 1963 Sukarno mengatakan bahwa:

\begin{tabular}{lrr}
\multicolumn{2}{c}{...ja, saja toepassen, saja } \\
trap-kan kepada situasi \\
masjarakat Indonesia. Dan \\
sebagai hasil daripada \\
penggunaan, atau toepassing \\
atau pentrapan historis- \\
materialisme Karl Marx \\
dimasjarakat Indonesia dengan \\
iapunja kondisi sendiri, dengan \\
iapunja sedjarah sendiri, iapunja \\
kebudadajaan sendiri dan \\
sebagainya lagi itu, maka saja \\
datang kepada adjaran \\
Marhaenisme" (Juti, 1964:8).
\end{tabular}

Marhaenisme menggunakan asas yakni sosio-Nasionalisme dan SosioDemokrasi. Hal ini yang menjadi landasan pemikiran Marhaenisme yang mencoba akan diterapkan pada masyarakat Indonesia.

1. Sosio-Nasionalisme adalah nasionalisme yang berperikemanusiaan, nasionalisme yang lapang dada, nasionalisme yang internasionalisme, nasionalisme yang bergetar hatinya untuk membela apabila melihat masih ada bangsa yang terjajah. Sosio-nasionalisme bukanlah nasionalisme yang berpandangan sempit dan menumbuhkan chauvinisme, intoleran atau disebut xeno phobia. Sosio-nasionalisme juga bukan nasionalisme yang hanya berorientasi pada internasionalisme minded saja, tanpa memperhatikan harga diri atau identitas nasional atau disebut xeno mania. Bagi Marhaenisme, internasionalisme harus dibarengi oleh nasionalisme atau patriotisme dan disebut sosio-nasionalisme (Anomim, dalam

WWW. marhaenisme.com, diakses pada 24 September 2011).

Sosio-nasionalisme diartikan sebagai nasionalisme masyarakat yang mencari keselamatan bagi seluruh masyarakat. Jelas nasionalisme Marhaen sangat anti terhadap sistem borjuisme yang menjadi penyebab kepincangan sistem dalam masyarakat. Sosio-nasionalisme juga merupakan nasionalisme politik dan ekonomi yang berusaha untuk mencari kemapanan politik dan kemapanan ekonomi. Kaum Marhaen harus terlepas dari gencatan kapitalisme dan mengobarkan semangat perlawanan kaum buruh dan mengorganisasikannya kedalam 
badan-badan serikat sekerja yang kuat (Ign. Gatut Saksono, 2008:51).

Sukarno menegaskan bahwa nasionalisme di dunia Timur itu lantas terpadu dengan Maxisme menjadi satu nasionalisme Baru. Nasionalisme Baru inilah yang kini hidup dikalangan rakyat Marhaen Indonesia yang harus tumbuh berkembang untuk mewujudkan kedaulatan yang sepenuhnya mampu menyelesaikan masalah-masalah kebangsaan yang dari dulu hingga sekarang tidak pernah kunjung usai seperti kemiskinan, penganguran, kebodohan, ketidak adilan, ketergantungan kepada asing, korupsi dan masalah masalah kebangsan lainnya yang itu mutlak harus diperangi (Yuddy Chrisnandi, www. marhaenisme.com, diakses pada 24 September 2011).

2. Sosio-demokrasi meliputi demokrasi politik dan demokrasi ekonomi. Demokrasi politik hanya akan melahirkan political power centris yang menyuburkan aliran yang berpedoman pada adagium "The survival of the fittest," dalil sosial Darwinisme. Menurut Sukarno, demokrasi politik yang seperti ini berwatak liberalisme dan menjurus kepada free fight competition dan bertentangan dengan Marhaenisme yang sosialistis. Dengan demikian, demokrasi politik dan demokrasi ekonomi sejajar dengan Marhaenisme.
Apabila Marhaenisme dikembangkan maka akan melahirkan Sosionasionalisme menjadi nasionalisme, perikemanusiaan dan Sosio-demokrasi menjadi demokrasi, kedaulatan politik dan keadilan sosial.

Demokrasi masyarakat tumbuh karena sosio-nasionalisme yang merangkulsemua seluruh kepentingan masyarakat Indonesia. Sosiodemokrasi sebagai reaksi dari demokrasi Barat. Menurut Sukarno demokrasi Barat dianggap lebih bersifat liberalis. Sementara pergerakan rakyat Marhaen lebih disebabkan karena kemerlaratan yang menginginkan kehidupan yang lebih baik dan sempurna. Perbaikan dalam sendi-sendi kehidupan bisa tercapai jika imperialisme dan kapitalisme telah hilang di negeri ini dengan syarat kemerdekaan dan kekuasaan ditangan Marhaen. Tantangan yang begitu besar bagi kaum Marhaen untuk melakukan sebuah pergerakan massa yang ingin mengubah sifat masyarakat sampai kepada akar-akarnya. Perubahan itu harus didukung oleh kemauan yang besar dari masyarakat sendiri dengan melakukan massa aksi (Ign. Gatut Saksono, 2008: 54-56).

Sukarno selalu memperingatkan kepada massa Marhaen untuk tidak meniru demokrasi yang dipraktekan di luar negeri. Dia yakin demokrasi seperti itu (parlementer) tidak akan menjamin 
hak-hak politik, tidak menjamin kesejarhteraan rakyat, dan menambah keterpurukan dalam bidang ekonomi. Mengenai bahaya Demokrasi barat (parlementer) Sukarno justru mengkritisi perjuangan kaum proletar yang tidak mendapatkan haknya setelah kemerdekaan karena demokrasi parlemen itu. Liberte, fransternite, egalite, hanya semboyan untuk membakar semangat massa namun setelah tujuan tercapai massa tidak mendapatkan haknya karena kapitalisme tetap subur dan memihak golongan atas ( Bernhard Dahm a.b. Hasan Basri, 1987:178-179).

Awas, kaum Marhaen, awas keborjuisan dan nasionalisme keningratan itu! Ikutilah hanya itu partai saja yang benderanya menyala-nyala dengan semboyan sosionasionalisme dan sosio-demokrasi, teriakkanlah semboyan sosionasionalisme dan sosiodemokrasi itu dengan suara yang mendengung menggetarkan langit, gemuruh sebagai guruhnya guntur. Dengungkanlah sampai melintasi tanah-datar dan gunung dan samudra, bahwa Marhaen seberangnya jembatan-emas akan mendirikan suatu masyarakat yang tiada keningratan dan tiada keborjuisan, tiada kelaskelasan dan tiada kapitalisme" (Sukarno, dalam Error! Hyperlink reference not valid.. wordpress.com., diakses pada 1 oktober 2011).
Sosio-Demokrasi yang merupakan asas bagaimana kelak susunan peri kehidupan kebangsaan di alam kemerdekaan dijalankan, dan dalam bidang ekonomi bagaimana susunan perekonomian harus dibangun agar dapat mengangkat martabat kaum Marhaen menuju kemakmuran, memerlukan cara-cara perjuangan. Cara perjuangan itu, tetap bertumpu bagaimana penguasaan alat-alat produksi dapat dilakukan untuk kemakmuran rakyat. Salah satu upaya setelah kemerdekaan adalah melakukan nasionalisasi perusahaan-perusahaan Belanda/Asing yang masih beroperasi di Indonesia.

Upaya ini dapat dipandang dalam rangka merebut alat-alat produksi, walaupun dalam pelaksanaanya ternyata alat-alat produksi itu tidak dikuasai oleh rakyat sebagaimana disyaratkan dalam sosio-demokrasi, tetapi dikuasai oleh aparat negara yang baru terbentuk, dengan mengatas namakan negara, untuk memperkaya diri. Kondisi kaum Marhaen dengan alat produksi yang dikuasai oleh asing maupun oleh bangsa sendiri tidak jauh berbeda. Kaum Marhaen tetap dijauhkan dari penguasaan alat-alat produksi di alam kemerdekaan, dan mereka tatap kaum kecil miskin dan melarat secara ekonomi, sehingga Marhaenisme tetap perlu diperjuangkan (Soeseno, dalam 
www.marhaenisme.com diunduh Pada 24 September 2011).

\section{PENUTUP}

Seorang Marhaen adalah orang yang mempunyai alat-alat yang sedikit, orang kecil dengan milik kecil, dengan alat-alat kecil, sekedar cukup untuk dirinya sendiri. Bangsa kita yang puluhan juta jiwa, yang sudah dimelaratkan, bekerja bukan untuk orang lain dan tidak ada orang bekerja untuk dia. Perkembangan paham marhaenisme tidak terlepas dari peran media massa dan berbagai organisasi yang digagas oleh Sukarno sebagai media komunikasi kaum intelektual akademis dengan massa. Selain itu kondisi masyarakat ketika itu hampir sebagian besar merupakan masyarakat subaltern sebagai akibat dari feodalisme dan kolonialisme.

Konsep Marhaenisme jelas merupakan sebuah kajian turunan dari konsep Marxisme, namun kemudian sukarno memodifikasi menjadi konsep yang sesuai dengan kondisi masyarakat Indonesia abad ke-20an. Kata Marhaen hampir sama dengan konsep proletar, kemudian untuk membedakan itu Sukarno memperluas arti kaum Marhaen. Jika kaum Proletar merupakan sekelompok buruh maka Marhaen mecakup petani miskin, pedagang miskin, dan rakyat miskin lainnya. Marhaenisme juga tidak terlepas dari pandangan politik Sukarno yang menginginkan persatuan seluruh rakyat Indonesia yang pada abad ke-20 sebagian besar adalah kaum miskin untuk melawan kolonialisme, imperialisme, dan feodalisme.

Konsep Marhaen terus dibawa oleh Sukarno pada perumusan dasar negara tahun 1945 juga setelah dia menjadi Presiden. Pemikiran itu telihat dari penyatuan unsur ideologi yakni (Nasionalisme Agama Komunis (Nasakom). Itu juga yang menjadi bumerang bagi Sukarno ketika terjadi tragedi berdarah 30 September 1965 yang membuat Sukarno lengser tersingkir dari kursi kepresidenan (lengser keprabon).

\section{DAFTAR PUSTAKA}

Anomim. "Marhaenisme dan Kekuatan Politik. Dalam www. Marhaenisme.com. diakses pada 24 September 2011.

Bernhard Dahm. "Sukarno and The Stuggle for Indonesian Independence", a.b. Hasan Basri. 1987. Sukarno dan Perjuangan Kemerdekaan. Jakarta: LP3ES.

I Ngurah Suryawan. 2010. Genealogi Kekerasan dan Pergolakan Subalter. Bara di Bali Utara. Jakarta: Prenada Media.

Ign. Gatut Saksono. 2008. Marhaenisme Ala Bung Karno: Marxisme ala Indonesia. Yogyakarta: Rumah Belajar Yabinkas.

Imam Toto K. Raharjo. dan Herdianto WK. 2001. Bung Karno Gerakan Massa dan Mahasiswa (Kenangan 
100 Tahun Bung Karno). Jakarta: Grasindo.

Juti. 1964. Sumbangan Pikiran Mengenai Marhaenisme. Jakarta: Yayasan BP. Lontarsari.

Nurani Soyomukti. 2008. Soekarno dan Nasakom. Yogyakarta: Garasi.

Peter Kasenda, "Sketsa Sosok Sukarno", www. peterkasenda. wordpress. com. Di akses pada 29 September 2011.

Sukarno. 1964. Di Bawah Bendera Revolusi. Jakarta. Yayasan Idayu.

Soeseno. "Marhaenisme dan Kedaulatan Ekonomi". Dalam www.Marhaenisme.com diunduh Pada 24 September 2011.

Sukarno. "Mencapai Indonesia Merdeka”. dalam Error! Hyperlink reference not valid. wordpress.com., diakses pada 1 Oktober 2011.

Yuddy Chrisnandi. "Marhaenisme dan Kekuatan Politik". dalam www. Marhaenisme.com, diakses pada 24 September 2011.

Yulianto Sigit Wibowo. 2005. Marhaenisme Ideologi Perjuangan Sukarno. Yogyakarta: Buana Pustaka. 